\title{
'VIDEOGAMETISM': CONSOLIDATING THE RECOGNITION OF VIDEO GAMES AS AN ART FORM
}

\begin{abstract}
Because video games are still considered 'low culture' by many whilst being one of the most important art forms of the XXI century, this paper proposes a new concept for the field of game studies with the main goal of being a useful tool for the consolidation of the artistic recognition of the medium. A few countries have officially recognized video games as an art form and implemented legislation to support video game artists and their work; unfortunately, many governments still do not recognize this artistic field. For video games to achieve a widespread artistic legitimation it is necessary more critical thinking and institutional validation. The proposed neologism - 'videogametism' - is an appropriation of the Eisensteinian concept of 'cinematism' and, as Sergei Eisenstein's legitimation term, 'videogametism' intends to support the recognition of video game artistic status, asserting that all art forms are present in this medium and that some artistic artifacts are 'videogamatic'.
\end{abstract}

Keywords: Art, Cinema, 'Cinematism', Gamification, 'Play', Video Games, 'Videogametism' 


\section{Introduction}

The field of game studies and the recognition of the 'artgames' category, "around 2007", allowed the growing legitimacy of video games as an art form (Parker, 2013). 'Artgames' embody a partial legitimation of the art of video games; the medium's artistic status needs to be reinforced by the creation of new concepts and more critical thinking, which will be useful on the 'journey' towards the inevitable universal validation of video games as an art form.

This paper proposes a neologism - 'videogametism' - which comes from the appropriation of Sergei Eisenstein's concept of 'cinematism'. The Russian filmmaker and theorist's goal was to give the new art form of cinema the corroboration it deserved. The appropriation of the author's concept proposed by this paper shares the same goal: valuing the artistic qualities of video games by exploring its interconnections to a myriad of other art forms. Many countries around the world do not recognize video games as an artistic medium; therefore, the 'videogametism' concept is a tool for the widespread validation of this art domain and its practitioners. Although the video game industry is the biggest entertainment industry in the world (Stewart, 2019), and one of the most important art forms in contemporary societies (Carita, 2015; Fuchs, 2015), it is still considered 'low culture'. The multidisciplinary production of video games and the artists that create them deserve the same institutional benefits as other artistic fields. Portugal, for example, a member of the European Union, has yet to recognize video games as an art form: the overall legitimation of video games has yet to be a reality in many countries, nevertheless, the multimedia aspect of the medium allows fragmented protection and legitimation of the final result.

Video games are complex works of authorship containing multiple art forms, such as music, scripts, plots, video, paintings and characters -that involve human interaction while executing the game with a computer program on specific hardware. Therefore, video games are not created as single, simple works, but are an amalgamation of individual elements that can each individually be copyrighted (i.e., the characters in a given video game, its soundtrack, settings, audiovisual parts, etc.) if they achieve a certain level of originality and creativity. (Ramos et al, 2013)

This paper will try to define the concepts of Art, 'cinematism', gamification, 'play', video games, and transmedia storytelling. These concepts do not have consensual definitions, hence, suitable theories were chosen to best present the concepts under the main theme of this paper. After establishing the importance of video games as one of the most significant art forms of the XXI century, the concept of 'videogametism' will be presented and analyzed as a useful tool to emphasize the inherited and intrinsically artistic qualities of the medium.

\section{Art and Video Games}

The history of Art is intertwined with the history of technology and technological innovation; scientific progress, the emergence of new tools, and new media have been massively relevant to artists and their artistic output (Ramos et al, 2013).

The definition of Art and its utility is controversial and complex in contemporary philosophy (Adaijan, 2018). The American philosopher George Dickie stated that the necessity of defining Art is old but not an impossible task. His 'institutional theory' establishes that Art is what is defined to be Art by the 'artworld'. For this author, the 'artworld' is a group of systems - theater, painting, sculpture, literature, music, etc. and subsystems, or niches, which accommodate the creative act. In essence: whatever the 'artworld' specialists consider being Art is Art. He established three historical phases for the search of a definition: the first corresponds to the various attempts to define Art, starting with the "imitation theory", followed by others such as the "expression theory"; the second 
is the negation that Art could be defined; the third phase - his 'institutional theory' - is the final definition, free of ambiguities and the difficulties of the traditional definitions (1984).

The American scholar Felan Parker wrote that the academy is a very important institution for the recognition of video games as an art form:

The growing legitimacy of games in general and indie games in particular is bolstered by scholarly attention to games, academic game studies, and the introduction of practical game design degrees and diplomas at colleges and universities. These institutions serve an important legitimating function, expanding the discursive and material opportunity space for the production and reception of digital games as a significant cultural form, and situating games alongside other legitimate art forms like visual art, theatre, literature, and film. (2013)

Parker identified the year of 2007 as a very important time, around which the 'artgames' genre emerged and, with this event, an "unusually high degree of cultural and artistic legitimacy" of the indie games category. He recognized that indie games and the subcategory of 'artgames' are unstable and ambiguous concepts since the video games included in these categories have distinctive qualities. Nevertheless, the author established a few possible non-universal common features: aesthetic originality, small development teams, and a conceptual message (2013). 'Artgames' seem to be to video games what 'auteur cinema' is for mainstream cinema: qualitative superior artifacts considered to be works of art.

The industry of video games, like the cinema industry, is a profitable business with artistic ambitions: some individuals aspire to create artistic artifacts and be recognized by the public, their peers, and the critics. The public (or consumer) is an important component of this industry and their interest in video games can be defined in several non-exclusive ways: entertainment, fun, knowledge, catharsis, and social status.

The validation of the 'artgame' genre arises with the launch of Jason Rohrer's Passage (Parker, 2013), in 2007. The curator Paola Antonelli selected this game, in 2012, to the permanent MoMA (Museum of Modern Art) collection. Her perspective on video games' artistic status is very clear: "Are video games art? They sure are, but they are also design, and a design approach is what we chose for this new foray into this universe" (2012). That same year the Smithsonian American Art Museum opened an exhibition entitled The Art of Video Games - one of the first displays dedicated to "the forty-year evolution of video games as an artistic medium". After several months at the museum, the exhibit went on a traveling tour (until January 2016) around the United States of America (SAAM, n.d.).

The specialized audience and some scholars seem to agree that video games are an art form but the general public still needs time to stop seeing them as just a distraction and a form of escapism. An important achievement would be widespread governmental legislation that legitimizes the artists working on this medium. Many countries have yet to recognize video games as an art form as others do:

The US National Endowment for the Arts (NEA) now considers video games eligible for artistic funding, meaning they are legally recognized as an art form. For those not familiar with the NEA, it is a US government program which funds artistic projects to "enhance the public good." In other words, the group decides which artistic projects are worthy of receiving federal funding. (Protalinski, 2011)

The United States of America federal government considers video games worthy of artistic merit (Protalinski, 2011) as well as a few other countries (e.g. France, Germany). All 
video game developers, video game designers, or video game artists from these countries have the opportunity of having their playable art pieces recognized as other artistic outputs from acknowledged art forms. This artistic merit should be globalized.

The 'artworld' is not blind to popular art forms still considered minor arts, such as video games and comics. The work of the American painter Roy Lichtenstein is well known, and his interest for the 'ninth art' is very much present in his portfolio; unfortunately, for many comics artists, Lichtenstein's work has little merit and his attempt to erode the distinction between 'high' and 'low' Art would eventually happen, without his contribution on the shoulders of unaccredited comics artists (Barnett, 2013). Many artists have been inspired by video games, and it's not uncommon to see video game aesthetics and designs on installations and new media art projects. Probably one of the most creative and recognized game-inspired pieces is the American artist Cory Arcangel's video installation Super Mario Clouds (the rightful appropriation credit is given on the title of the work). This 2002 piece resulted from the hacking of a cartridge of a Super Mario Brothers game and the erasing of all game elements except the iconic scrolling clouds over a deep blue sky, representing a critical approach to the neck-breaking speed of modern life and the "lightning-fast cycle of technological turnover" through the use of a retro game (Whitney Museum of American Art, n.d.). Another recognized art form that has been adapting stories and characters from video games is cinema: this medium, known for its intermediality, has been adapting narratives from literature, comics, and theater since its infancy; nowadays, it's not uncommon to see video game adaptations on the big screen (e.g. Resident Evil). Moreover, the long narrative format of TV series (or streaming services) is not unaware of the potential of video game narratives and 'storyworlds', therefore, TV producers have been adapting video games (e.g. Castlevania) to the satisfaction of fans and 'fandom'.

\section{Defining Video Games and 'Play'}

The definition of video games doesn't yet exist in its plenitude because the concept is in constant turmoil (Carita, 2015). A video game, according to the online dictionary Merrian-Webster, is an electronic game where players control images on a screen (video game, n.d.). Agreeing with this definition, the first video games are considered to be Tennis for Two (1958) and Spacewar! (1962). The video games industry gave its first steps with arcade games such as Pong (1972) and, after that, consoles and desktops allowed video games to enter our homes. Nowadays, digital games or game apps for smartphones and tablets are very common and ubiquitous. The interfaces of these extensions of our minds - smartphones and tablets -, connected to the Internet, coincide more and more with tactile screens that allow the control of images on a screen. One could say that this video game-defining characteristic has become transversal to the many tasks that are a part of our daily lives and that we live in an increasingly 'videogamatic' world.

Video games are not just one more medium to produce artistic artifacts; it is also one of the most important ones in the contemporary world. The Portuguese teacher André Carita did a critic rereading of the Umberto Eco 'open work' concept - a work of art is open to infinite interpretations and affirmed that the video game is the maximum expression of 'open work'. For the Portuguese scholar, the art of video games is permeable to other forms of art and a modern reply to an ancestral need of humankind - 'play'. Carita believes that video games, as an 'open work', are the most important bridge between technology, Art, communication, culture, and innovation, as well as one of the most permeable platforms to human creativity and the flexibility of our minds (2015).

To understand games and the video game phenomena, it's crucial to understand why Homo sapiens needs to play. Why is this activity so important for our species? The Dutch 
Historian Johan Huizinga stated that many animals play as we do and the act of playing goes beyond our immediate life necessities, and it's more than a psychological reflex or a physiological phenomenon. To Huizinga, 'play' is, above all things, fun. He defines it as a fundamental voluntary activity, executed in a certain space and timeframe, subjected to certain rules. It's a moment of tension and happiness where the player is aware of the activity, and it promotes social engagement (1949).

The American scholar David Whitebread et al. stated that playing is important to human development and defined five specific categories: 1) "physical play"; 2) "play with objects"; 3) "symbolic play"; 4) "pretense or sociodramatic play"; 5) "games with rules". The first category corresponds to the physical games that can go from jumping, climbing, and ball play, to fine-motor activities like coloring, sewing, and building toys. The most researched aspect of this category, believed to have evolved as an aggressiveness control mechanism, is the "rough-and-tumble", which include activities such as pursuing, grabbing, kicking, fighting, and rolling on the ground. The second category, "play with objects", starts immediately when the baby can grab and it goes from biting to beating and throwing; this category is intertwined with the first. The third category is closely related to our symbolic systems such as spoken language, reading, writing, mathematics, visual media, music, etc. Children love inventing words, rhyming, making puns, and telling jokes. They also enjoy singing and drawing. Visual literacy, for example, comes from their contact and experiences with a variety of visual media (including video games). The fourth category - "pretense or sociodramatic play" - is "the most prevalent type of play amongst young children", and "the most heavily researched". Children who play this way become less disruptive and more social. This is also a common type of 'play' amongst adults: Carnival, Halloween, RPG's (role-playing games), 'cosplay' (costume play), immersive theater, etc. The fifth and last category is "games with rules"; because children are very interested in the rules of the world this category is very important, as they often invent their games and rules. When they are younger, they enjoy physical games such as hide-and-seek; when they grow older they prefer sport activities and "more intellectual games such as board and card games, electronic and computer games" (2012).

Creating imaginary or 'secondary worlds' is a very important activity for both adults ('worldbuilding') and children ('paracosm'). The creative construction of 'storyworlds' is a very important component in some 'play' categories and the production of several video games (and other media outputs).

The earliest experience of creating and exploring imaginary worlds often occurs in childhood play. Children create their own fictional universes - labelled "paracosms" by psychologists in the field - to house their games of make-believe. This activity is often extended throughout adolescence with an engagement with toys, board games, and video games, where play is removed even further from direct experience. (Wild, 2016)

The American scholar Tom Chatfield stated that humankind has been playing games since before we invented writing and, perhaps, even before we started speaking (qtd. Romualdo, 2013). Our species is considered to be a technological animal since it came into being as an autonomous species: our relation with technology predates Homo sapiens and is a cornerstone in our development. Without technology and a few paradigm-changing inventions or technological breakthroughs, the emergence of humankind, as we know it, wouldn't be possible. An interesting fact about the lithic industry and the controlled use of fire is that both technologies were very important in our evolutionary path and predate our species. The British primatologist Richard Wrangham, with his 'cooking hypothesis', explained the radical evolution inside the Homo genus, specifically from the Homo habilis to the Homo erectus. The use of fire 
to cook food allowed the chewing process to be more efficient, and it reduced the energetic cost of digestion and the body investment in immune defenses due to the ingestion of raw meat. Because cooked food digestion is more efficient, it may have allowed humans to obtain higher energetic value from food, resulting in less time wasted in eating, and "brain size increase". Wrangham also reflects on how the lithic industry could have initiated this process: the Homo habilis was able to soften food mechanically, by using stone instruments to "cut and pound food" (2017). If proven correct, Wrangham's hypothesis acknowledges our proficiency to use tools and technology to our benefit (and to serve us in our playful and artistic activities). Video games and video game art were inevitable consequences of our technological evolution and necessity to 'play'.

The British philosopher Alan Watts had a controversial notion of life and 'play'. He believed that existence is a game and should not be taken too seriously: "Now it is my contention and my personal opinion - this is my basic metaphysical axiom, shall we put it that way - that existence - the physical universe - is basically playful". For Watts, life should be lived to its fullest (2019). It's impossible not to think about the film La Vita è Bella, by Roberto Benigni, where the protagonist, while trying to protect a child, minimizes the horrors of war by pretending it's all a game. In a sense, the protagonist gamified his reality to make it less painful, which shows us that games can help people cope with hard times.

\section{Gamification and Transmedia Storytelling}

The dictionary definition of 'gamification' is that it is "the process of adding games or gamelike elements to something (such as a task) so as to encourage participation" (gamification, n.d.). The concepts of 'serious games' and 'serious play' show us that the definition has to be broadened because encouraging participation is not the only goal when using gamelike elements in our daily lives and work contexts.
The German scholar Mathias Fuchs understands gamification as "the process of a total permeation of our society with methods, metaphors, values, and attributes of games", and that the use of game elements in non-game contexts is much older than the neologism, which was coined in 2002, by the British-born author Nick Pelling. Fuchs claims that we are reaching a period of nefarious total gamification of the world, resulting in the saturation of 'play' and the downfall of the game medium. He also believes that games have reached their maturity, surpassing their obvious mediality and that they are one of the most important media in contemporary societies: their ability to "cannibalize" other media, the development of serious games and gamified learning, and their ubiquity through mobiles and other means have allowed games to reach almost every social group of the population (2015).

The gamification of the world will hardly result in the downfall of the games medium, as the ubiquity of screens didn't result in the downfall of audiovisual narratives. The cinematographic and audiovisual stories we consume nowadays are as important as the stories that were told and read before the hegemony of the 'moving image'. The way we tell stories and the stories we tell have a close relation to the many technologies we use: video games can be characterized as being another storytelling medium ('videogamatic' storytelling) but they are not limited by their narrative possibilities.

Transmedia storytelling - the apex strategy/aesthetic in contemporary narrative production - is defined by the fragmentation of a story throughout multiple platforms to offer more and better content to the consumer, who is transformed into a kind of modern information hunter-gatherer (Jenkins, 2007). Many consumers, nowadays, are also producers, due to the democratization of technology and the means of spreading creative content. The strategic research work of a 'prosumer' (consumers that produce content about their favorite themes), often done online, can be recognized as a 
sort of gamified activity due to the game elements involved. The big franchises tell their stories through several media and sometimes hide or disguise information: what the fans call 'easter-eggs'. A franchise such as the MCU (Marvel Cinematic Universe), for example, is in itself a kind of gamified system a metaphorical egg-hunt - that allows fans to search and research the information they need to create their theories and reviews, which are then shared online through articles, posts, and video essays.

Transmedia storytelling allows for a story to be broken into several pieces and be told through several media, including games and gamified activities. The American scholar Henry Jenkins believes that in the era of Cultural Convergence, fans network with ease and create content collectively using intuitive digital tools. For him, this is the result of a media convergence that creates new challenges for both consumers and producers. The convergence is not so much about technology, but a 'cultural convergence' linked by three basic concepts: media convergence, participatory culture, and collective intelligence (2006).

The American transmedia producer Jeff Gomez, in an interview for Indiewire, shared three basic rules for transmediating a narrative: 1) the story must have positive qualities that inspire the public; 2) the production team must have adequate technical skills; 3 ) the relation between transmedia producers and fans must be carefully woven, validating their participation (Bernstein, 2013). The relation between the producers of transmedial franchises and the fans will be much stronger if they implement 'gamification strategies' and interactive storytelling strategies. The Belgian gamification designer An Coppens, on her Gamification Nation podcast, defined 'gamification strategies' as a kind of enriched communication approach that can be used by companies through games, video games or gamified processes to please their audiences (2020). Much like transmedia storytelling, the goal is to elevate the consumer's experience.
So, for example, in The Matrix franchise, key bits of information are conveyed through three live action films, a series of animated shorts, two collections of comic book stories, and several video games. There is no one single source or ur-text where one can turn to gain all of the information needed to comprehend the Matrix universe. (Jenkins, 2007)

Now that the Matrix universe is being revisited with a fourth action film, it's expectable to see the production of comics and video games that will be part of the transmedial strategy for the franchise. This will also happen with the 'remediation' of the Dune (1965) novel by the American director Denis Villeneuve - two feature films and a TV series will restart this remarkable franchise. Board games and video games have already been announced. Video games, gamification, and transmedia storytelling are closely intertwined and it's impossible, nowadays, to think of a transmedial franchise without sections of the overall narrative being adapted or transmediated to the video game medium.

\section{'Cinematism' and 'Videogametism'}

Etymologically, the word 'cinema' is short for 'cinematograph', which comes from the French term 'cinématographe' (the multifunction machine the Lumière brothers designed). Breaking down the word cinematograph we have the Greek word 'kinema', which means 'motion' (cinematograph, n.d.) and the Greek word 'graphos', which means 'drawn' or 'written' (-graph, n.d.). Therefore, cinematograph and its shorter version, cinema, can be understood as the 'writing of motion'.

The suffix 'ism' can be used for several ends but in the case of 'cinematism', it's a state, a property, or a condition (ism, n.d.) of the moving image, much like barbarianism is a property of being barbarian. Another definition - "a distinctive doctrine, cause, or theory" (ism, n.d.) - is very interesting and of great 
relevance to this paper. The French scholar Ada Ackerman accurately stated that Sergei Eisenstein didn't use the term 'cinematism' on his texts, which derived from the French word 'cinématique'. He spoke of 'kinematografichnost', which may be translated as 'cinematographicity' (2016). The widespread use of the term 'cinematism' in Eisensteinian Studies, to name the author's concept, was key for the decision of using it in this paper.

Eisenstein searched for the justification of the legitimation of cinema as an art form, through the concept of 'cinematism', showing the historical inevitability of this medium sprouting from the 'older' arts (Kleiman, 2016). Eisenstein was interested in elevating cinema as an art form without forgetting its heritage:

I don't know how my readers feel about this, but for me personally it is always pleasing to recognize again and again the fact that our cinema is not altogether without parents and without pedigree, without a past, without the traditions and rich cultural heritage of the past epochs. It is only very thoughtless and presumptuous people who can erect laws and an esthetic for cinema, proceeding from premises of some incredible virgin-birth of this art! (Eisenstein, 1977)

The French scholars Jacques Aumont and Michel Marie defined 'cinematism' on their book - Theoretical and Critical Dictionary of Cinema - as a neologism created by Eisenstein to designate the cinematographic characteristics of certain artistic experiences (qtd. Dassie, 2019). Eisenstein was very interested in the relation between cinema and other arts and defined their relationship as organic and genetic (Dassie, 2019). The intermediality and heritage of cinema is a defining characteristic of its relationship with other art forms. 'Cinematism' establishes that all arts are present in cinema and that many arts are cinematic, even if they were created before the advent of cinema (Polidoro, 2008).
The video games organic relationship with other art forms, its heritage, and the lack of widespread recognition, were important factors for the decision of appropriating the Eisensteinian neologism and 'creating' the 'videogametism' concept: all arts are present in video games and some artistic artifacts are 'videogamatic' or possess video game characteristics. The appropriation of 'cinematism' in this context aims at the elevation of video games as an art form by its own merits.

The Portuguese scholar Sofia Romualdo stated that, like other popular art forms such as photography, comics, and street art, video games have been neglected until very recently and denied the attention and legitimacy it deserves. She identified that the attention the 'artworld' has been giving to video games and its possibilities as a medium have transformed the video game industry. Moreover, she stated that to achieve "a more widespread acceptance as a legitimate art form" there should be more critical thinking about video games and institutional validation through "exhibitions, collections, studies and contextual framing" (2014).

The American scholar Mark Wolf wrote that video games are one of the most important themes in new media studies and that it has been accepted, by the academy, as a very rich, polysemic, and dynamic field of expertise:

The video game is now considered as everything from the ergodic (work) to the ludic (play); as narrative, simulation, performance, remediation, and art; a potential tool for education or an object of study for behavioral psychology; as a playground for social interaction; and, of course, as a toy and a medium of entertainment. (Wolf \& Perron, 2003)

If some people of the academy, the industry, and the 'artworld' agree on the artistic legitimacy of video games, the universal recognition of the medium is inevitable. Before that goal is achieved, the defenders and the harbingers of the 
video games art must be armed with new concepts and arguments. The 'videogametism' concept must be understood as follows: it is an ideology that defends the artistic component of the medium, the intermediality of video games, their heritage, and the presence of video game characteristics in other artistic projects - the use of gamelike features by other artistic media must be considered 'videogamatic'. And, as it happens in cinema, not all video games should be considered Art; some films, as some video games, are just consumable products with no artistic aspirations but that should not be an argument against the recognition of the medium.

\section{Conclusion}

The video game medium has reached its maturity (but not its full potential) and is one of the most important media of this century. However, the lack of a broader institutional and universal recognition of its intrinsic artistic nature needs to be further addressed.

A few countries (e.g. France, Germany, U.S.A) have legally recognized video games as an art form. The academia - games studies and media studies - has been addressing the artistic component in-depth, and some people in the 'artworld' recognize the artistic qualities of the most profitable entertainment industry around the globe. Gamification is a very powerful concept for the study of the importance of games and 'play' in all aspects of the human experience, however, due to its broad definition and application, it does not convey in full the possibility of being used as a tool for the recognition of video games art. 'Artgames' as a genre is too much of a niche to be of assistance with the necessary universal acknowledgement of the medium. Transmedia mainstream franchises are not very interested in the artistic side of video games, but rather on the narrative potentiality and the commercial benefits the medium can offer.
Sofia Romualdo wrote that for video games to achieve "a more widespread acceptance as a legitimate art form" there should be more critical thinking about video games and institutional validation through "exhibitions, collections, studies and contextual framing." Through the contextual framing of a 'new' concept - 'videogametism' - this paper's goal is to help shorten the 'voyage' towards the institutional and universal recognition of video games as an art form. The growth of the video game industry is undeniable and, as it happens with cinema creators, the ambition to design playable works of art by some game designers or developers is a 'necessity'. It is inevitable that the artistic quality of video games further increases in the following decades; therefore, new concepts are important for the critical thinking necessary to assure the widespread recognition of the medium. As once Sergei Eisenstein felt that cinema needed a new concept to study the validation of the medium, maybe the appropriation of his neologism could be pertinent for the artistic field of video games.

\section{References}

Ackerman, A. (2016). What Renders Daumier's Art so Cinematic for Eisenstein? In Naum Kleiman \& Antonio Somaini (Eds.), Sergei M Eisenstein: Notes for a General History of Cinema (pp. 255-265). Amsterdam: Amsterdam University Press.

Adaijan, T. (2018, August 14) The Definition of Art. Stanford Encyclopedia of Philosophy. https://plato.stanford.edu/entries/ art-definition

Antonelli, P. (2012, 29 November). Video Games: 14 in the Collection, for Starters. Inside/Out. www.moma.org/explore/ inside_out/2012/11/29/video-games-14-in-the-collectionfor-starters

Barnett, L. (2013, March 4). A comics artist's viewon Lichtenstein: A Retrospective. The Guardian. www.theguardian.com/artanddesign/2013/mar/04/comic-artist-view-roy-lichtenstein 
Bernstein, P. (2013, December 3). The 3 Rules of Transmedia Storytelling from Transmedia Guru Jeff Gomez. IndieWire. www. indiewire.com/2013/12/the-3-rules-of-transmedia-storytelling-from-transmedia-guru-jeff-gomez-32325

Carita, A. (2015). Pensar Videojogos: Design, Arte e Comunicação. Lisboa: Edições Universitárias Lusófonas.

Cinematograph (n.d.). Dictionary.com. Retrieved April 16, 2020, from www.dictionary.com/browse/cinematograph

Coppens, A. (Producer). (2020, March 24). Podcast 38: What is a gamification strategy? [Audio podcast]. www.gamificationnation.com/podcast-38-what-is-a-gamification-strategy

Dassie, F. A. (2019). Cinematismos/ babilaques/ leituras. ALEA: Estudos Neolatinos, Vol. 21 (1), pp. 93-110. https://dx. doi.org/10.1590/1517-106X/21193110

Dickie, G. (1984). The Art Circle: A Theory of Art. New York: Haven.

Eisenstein, S. (1977). Film Form: Essays in Film Theory. New York \& London: A Harvest/ HBJ Book.

Fuchs, M. (2015). Total Gamification: Introduction. In Mathias Fuchs (Ed.), Diversity of Play (pp. 7-18). Lüneburg: Meson Press.

Gamification (n.d.). Merriam-Webster.com dictionary. Retrieved April 16, 2020, from www.merriam-webster.com/dictionary/ gamification

-graph (n.d.). Dictionary.com. Retrieved April 16, 2020, from www.dictionary.com/browse/-graph

Huizinga, J. (1949). Homo Ludens: A Study of the Play-Element in Culture. London: Routledge \& Kegan Paul Ltd. ism (n.d.). Merriam-Webster.com dictionary. Retrieved April 16, 2020, from www.merriam-webster.com/dictionary/ism

Jenkins, H. (2006). Convergence culture: Where old and new media collide. New York: New York University Press.

Jenkins, H. (2007, March 21). Transmedia Storytelling 101. Confessions of an Aca-Fan. http://henryjenkins.org/ blog/2007/03/transmedia_storytelling_101.html

Kleiman, M. (2016). Foreword. In Naum Kleiman \& Antonio Somaini, Sergei M Eisenstein: Notes for a General History of Cinema (pp. 13-17) [Foreword]. Amsterdam: Amsterdam University Press.

Parker, F. (2013). An Art World for Artgames. Loading... The Journal of the Canadian Game Studies Association, Vol. 7(11), pp. 41-60. http://journals.sfu.ca/loading/index.php/loading/ article/view/119/160

Polidoro, B. (2008). Cinema, Vídeo, Digital: A virtualidade do Audiovisual. Sessões do Imaginário - Cinema / Cibercultura / Tecnologias da Imagem. Vol. 13(19), pp. 1-5. http://revistaseletronicas.pucrs.br/ojs/index.php/famecos/article/ view/4153/3165

Protalinski, E. (2011, May 9) The US legally recognizes video games as an art form. Techspot, www.techspot.com/ news/43696-the-us-legally-recognizes-video-games-as-anart-form.html

Ramos, A., López, L., Rodríguez, A., Meng, T., Abrams, S. (2013). The Legal Status of Video Games: Comparative Analysis in National Approaches. Geneva: World Intellectual Property Organization. www.wipo.int/export/sites/www/copyright/ en/activities/pdf/comparative_analysis_on_video_games.pdf 
Romualdo, S. (2014). Playable Art: Towards the Legitimization of Videogames as an Art Form. Videojogos 2014 - Conferência de Ciências e Artes dos Videojogos. pp. 137-142. http:// web.ipca.pt/videojogos/atas/18_VIDEOJOGOS_2014.pdf

Romualdo, S. (2013). Play, Games and Gamification in Contemporary Art Museums [Master's thesis, University of Oporto]. Academia. www.academia.edu/16287629/Play_Games_ and_Gamification_in_Contemporary_Art_Museums

SAAM (n.d.). The Art of Video Games. Smithsonian American Art Museum. https://americanart.si.edu/exhibitions/games

Stewart, S. (2019, October 22). Video game industry silently taking over entertainment world. EJ Insight. www.ejinsight. com/eji/article/id/2280405/20191022-video-game-industrysilently-taking-over-entertainment-world

video game (n.d.). Merriam-Webster.com dictionary. Retrieved April 16, 2020, from www.merriam-webster.com/dictionary/ video\%20game

Watts, A. (2019, April 16). 1.1.4. - Coincidence of Opposites. www.alanwatts.org/1-1-4-coincidence-of-opposites

Whitebread, D., Basilio, M., Kuvalja, M., \& Verma, M. (2012). The importance of play. Toy Industries of Europe. www.csap. cam.ac.uk/media/uploads/files/1/david-whitebread---importance-of-play-report.pdf

Whitney Museum of American Art (n.d.). Cory Arcangel: Super Mario Clouds, 2002. Whitney Museum of American Art. https://whitney.org/collection/works/20588

Wild, G. (2016). Visual World-Building: Developing a Conceptual Framework for Concept Design in Fantasy Role Playing Games. [Unpublished dissertation]. James Cook University.
Wolf, M., Perron, B. (2003). Introduction. In Mark Wolf \& Bernard Perron (Eds.), The Video Game Theory Reader (pp.1-24) [Introduction]. New York: Routledge.

Wrangham, Richard (2017). Control of Fire in the Paleolithic: Evaluating the Cooking Hypothesis. Current Anthropology, Vol. 58(16), pp. 303-313. www.journals.uchicago.edu/doi/pdfplus/10.1086/692113 